\title{
Violence Against Women in Sanaa Shalan's Falling in the Sun
}

\author{
Saif AL Deen Lutfi Ali AL Ghammaz ${ }^{1}$, Ruzy Suliza Hashim¹ \& Amrah Binti Abdulmajid ${ }^{1}$ \\ ${ }^{1}$ Universiti Kebangsaan, Malaysia \\ Correspondence: Saif AL Deen Lutfi Ali AL Ghammaz, Universiti Kebangsaan, Malaysia. E-mail: \\ s_algammaz@yahoo.com
}

$\begin{aligned} & \text { Received: December 31, } 2019 \\ & \text { Accepted: February 1,2020 Online Published: February 21, } 2020 \\ & \text { doi:10.5539/ells.v10n1p53 }\end{aligned}$ URL: https://doi.org/10.5539/ells.v10n1p53

\begin{abstract}
Violence against women is a heinous act committed against a woman, a wife, a mother, a sister, or even a daughter deliberately or not deliberately causing her psychological, emotional, and physical harm. The rise of this unhealthy phenomenon mainly in less-developed countries such as Jordan necessitates more academic attention not only because of its detrimental effect on the Jordanian women's lives, but also because it is intentionally ignored and dismissed as taboo. With that, there has been a growing interest among Jordanian writers and sociologists in exploring the extent of this social ill through creative literary genres such as novels. This paper for one primarily examines the manifestations of violence against women in the Jordanian context through a textual analysis of Falling in the Sun by Sanaa Shalan, an author hailing from the contemporary Jordanian generation. Originally written in Arabic, this well-known novel gives prominence to the severe reality of the distress habitually suffered by many Jordanian women, notably the various forms of violence that they have to tolerate living in a multicultural male-controlled nation. With a feminist reading of Falling in the Sun (2014), we shall examine Shalan's representations of violence against women in the novel as a dire social illness resulting from mistaken social beliefs, absence of laws, and misunderstanding of religion and gender inequality in the Jordanian society. Additionally, the current paper's outline is constructed on three main forms of violence against women, i.e. physical, psychological and economic abuse as depicted in Falling in the Sun through the novel's female characters, primarily the main protagonists.
\end{abstract}

Keywords: volence against women, Sanaa Shalan, Falling in the Sun, Jordanian fiction, masculinity, gender-based violence

\section{Introduction}

Jordanian literature in the second half of the twentieth century witnessed a significant and evident shift in women's writings, and the literary scene is now filled with dozens of Jordanian female writers and novelists. Several Jordanian female writers such as Sanaa Shalan, Fadia Faqir, Laila al-Atrash, and Basma al-Nsour have spoken on issues related to women. Munira Salih (2010, p. 4), however, expresses her regret that "Literature, in large part, either still portrays women as they attach most of their hopes to men or as a simple mother who has no constituents of life except to pray". In this paper, we focus on Sanaa Shalan, an eminent Jordanian woman writer who has bravely addressed realities of Jordanian women, especially in matters devoted to domestic violence.

The United Nations General Assembly in 1993 defined the term "domestic violence" as any violent act that leads to exposing women to any kind of harm be it physical, sexual or psychological in her private or public life. Women's advancement and development to the level of its rightful place have become one of the key contemporary issues that governments, international institutions and private bodies are still working on. This issue has been the agenda of many successive international conferences since the early nineties, where a wide range of international principles and standards have been adopted to protect the social, economic, cultural and civil rights of women. For instance, the Fourth International Conference on Women in Beijing in 1995 drew several outcomes on the issue of violence against women which cover important areas such as making efforts to prevent and eliminate violence against women through organized and meaningful programs, investigating the roots of the issue along with its effects on women, family and society and assisting victimized women to see their perpetrators held accountable for their crime in courts.

Against this background and on the Jordanian level, Jordan participated in these conferences and ratified the major terms of agreements that helped in advancing Arab women's status; however, reservations on many 
articles and items in these agreements still exist. In one of the reports issued by the Office of the High Commissioner for Human Rights, the Human Rights Officer/Regional Gender Advisor, Darwazeh (2012) reaffirms what was previously mentioned Convention on the Elimination of All Forms of Discrimination against Women (CEDAW), saying "The Convention defines discrimination against women as any distinction, exclusion or restriction made based on sex which has the effect or purpose of impairing or nullifying the recognition, enjoyment or exercise by women, irrespective of their marital status, on a basis of equality of men and women, of human rights and fundamental freedoms in the political, economic, social, cultural, civil or any other field". She adds that "by accepting the Convention, States commit themselves to undertake a series of measures to end discrimination against women in all forms, including to incorporate the principle of equality between men and women in their legal system, abolish all discriminatory laws and adopt appropriate ones prohibiting discrimination against women, to establish tribunals and other public institutions to ensure the effective protection of women against discrimination, and to ensure elimination of all acts of discrimination against women by persons, organizations or enterprises".

As a result, several countries have made decisions to accede to the provisions of the said Convention and put them into action by providing national reports on a 4-year term, proving that there are new measures and practices taken to comply with the obligations of the said Convention. Yet, Jordan has made reservations on certain articles of the CEDAW Convention and the Committee on the Rights of the Child (CRC) as well. Moreover, Jordan has not acceded the CEDAW convention's optional protocol related to individual complaints.

The resolutions demonstrate zero-tolerance for domestic violence. Whether any of these declarations appear in the Jordanian works that deal with domestic violence is an important basis of inquiry in this study. Within the Jordanian context, domestic violence is not a new term or issue because the numbers and statistics demonstrate that it is a widely spread phenomenon. It is known that a huge number of women have been abused in several areas in Jordan namely the center, the villages and the southern remote areas. Based on statistics in Jordan, the most widespread form of violence is physical cruelty and the most exposed victim to this violence is women. Al-Badayneh (2012, p. 1) revealed that: "Findings showed women experienced $45 \%$ or witnessed $55 \%$ violence during their childhood. Almost all $98 \%$ of the sample was subjected to at least one type of violence". In Jordan, there have been efforts to eliminate forms of discrimination against women through the provision of education and employment opportunities for women in order to improve their public and private lives within the family and to eliminate gender stereotypes. Moreover, there have also been attempts to protect the rights of girls to raise awareness on gender discrimination and its removal within the same family since it leads to imbalances such as the forcing and impelling of females to get married at a very young age. Out of these efforts, the Jordanian National Commission for Women (JNCW), the United Nations Country Team in Jordan, the Tamkol—Gender Program of the United States Agency for Development and the Dutch Embassy in Amman ran a 16-Day Campaign against Gender-Based Violence in Jordan, where the UN Gender Group involved several parties in the communities in the campaign, with particular emphasis on involving men and boys in reducing violence against women and girls. Another example of these efforts is a 16-minute film entitled "Violence against Women" which depicts violence against Jordanian women produced by Sisterhood is Global Institute Jordan (SIGI) at the Family Reconciliation and Guidance Center in Amman in 2013. Based on this grim picture of the prevalence of domestic violence in Jordan, it is timely to see how it is represented in Jordanian literature.

\section{Literature Review}

Shalan is a Jordanian author who was born and educated in Amman, Jordan. She gained her Ph.D in Modern Arabic Literature from the University of Jordan in 2006. Shalan is a contemporary prolific writer who has produced three novels, more than twenty anthologies of short stories, eight children's short stories, three academic books, memoirs and essays. In her works, Shalan explores several areas of romantic, human and children literature, criticisms, issues of human rights, women, childhood, social justice, human rights, the environment and other political issues. Sowadiyya (2013, p. 12) asserts: "Shalan is always revolting against the unconstitutional and unacceptable traditions and restrains practiced against women in her community". Shalan's novels provide genuine reflections of the reality of the problem and its magnitude in Jordan. he way the writer addresses the issue of violence with all its forms reflects the continuous cycle of violence and the extent to which women are facing gender problems in their communities.

Violence against women as a social illness is not an offshoot of Shalan's imaginative skills in prose writing, but rather a reality genuinely depicted in Falling in the Sun. Haddad (2016, p. 2) asserts: "Women in Jordan are positioned in a construct administrated by rigid family, tribal and religious norms fueling discrimination and violence against them on a daily basis". Similarly, "The violence hindering and threatening a huge percentage of Jordanian females' lives is deeply embedded and inherited in the Jordanian culture, norms, attitudes, and acts" 
(JNCW, 2010, p. 16).

With the agenda of eliminating the scope of gender-based violence and supporting the formation of an equal society, Shalan through her first novel Falling in the Sun had successfully illustrated the actual daily lives of ordinary Jordanian women. The novel, her first literary work in Arabic, has been considered as moving, provocative and tragic upon its release. Set in Jordan in the late nineties, it is hence noteworthy to trace the prevalence of female oppression and women's social standing. The novel's title is a metaphorical representation of someone falling in the hot sun, alluding to the female heroine, Zahra whose falling in the sun leads to her victimization, pain and suffering. The novel revolves around Zahra who is always fearful of her father, a man who oppresses his daughter and wife, Fatima. Her father is well-known as a religion-adhering man who always prays and calls for people to abide by the Islamic law. Zahra's childhood was filled with abuse as her father hates having female children. Since her face was full of pimples, her father thinks that she will never marry and thus remain a burden on him and his son Ahmed when he grows up. Due to this, Zahra dreamt of marrying a person whom she loves and who would save her from her father's unjust treatment. Alas, her dream was shattered when she married Majid who is an exact replica of her abusive father. After divorcing Majid and embarking on a new life, she experiences another abuse by her workmate, Malik, who beats her violently after failing to rape her. Through the portrayal of Zahra, Shalan presented a clear critique on the prejudices, marginalization, gender inequality and continuous cycle of female oppression prevailing in Jordan's masculine society.

Several past articles have been written on Sanaa Shalan's Falling in the Sun, but none had focused on the issue of violence against women in particular. The novel had been explored from various perspectives such as romanticism, human and children literature, criticism, issues of human rights, women, childhood, social justice, human rights, the environment and other political issues. In his 2012 study Dimensions of the Universe in Falling in the Sun, Khaled Yaboudi focuses on how to read a novel from two different perspectives: the science fiction that employs scientific data for imagining the future, as well as the fantasy literature that employs invisible forces opposing the logic, thus falling within the scope of metaphysics. Hassan, in his 2017 article Stream of Consciousness in Falling into the Sun, emphasised on the psychological and metaphorical sides of the novel, stating that the title of the novel clearly expresses an emotional and psychological need for purity and transcendence; that it is a mental expression of salvation for a self that refuses to fall on the ground but rather to rise and fall into the sun. Metaphysically speaking, he adds that the title indicates the trend of dependent existence, where the sun is a mirror that reflects light and warmth on every planet in our solar system. Thus, a human being, as an entity in himself, builds his relations based on what he perceives from the cosmic entities around him.

\subsection{Conceptual Theory}

Feminism is a set of ideologies and movements entirely aimed at achieving the social, gender, economic, personal and political rights of women as well as ensuring the abolition of gender stereotypes. It aims to create equal opportunities and positive social standing for women in society so as to eradicate all forms of violence against them due to the prevalent gender inequality. Accordingly, feminism offers a large scope of examination and analysis on violence against women by addressing the reasons, basis and rising number of cases worldwide with regards to the phenomena (Haddad, 2009). That being said, the significance of feminism as a literary theory lies in examining the women's unceasing victimization and marginalization in a male-controlled culture and a social construction organized in support of men (Nsour, 2008).

From a feminist perspective, the most noteworthy concept related to the problem of violence against women is discrimination and gender inequality, which advocates all approved stereotypical gender roles and consequently justifies the widespread concept of patriarchy. And of course, feminism strives for equal social and political opportunities for women in society and the eradication of all forms of violence against them, mainly those that are naturally created. Engendered violence includes abuses and violations against human rights, together with other forms of abuses such as physical and physiological abuse, rape, sexual assault and harassment, and domestic violence. It is the most ubiquitous yet least-documented abuse of human rights in the world (Harne \& Radford, 2008). Addressing the phenomenon of violence against women as a key form of gender-based discrimination and human rights deprivation creates a platform to clarify the issue, alongside the whys and wherefores behind its occurrence and pervasiveness in the world regardless of religion, race and culture.

From a feminist standpoint, violence against women can be defined as "a major public health problem, a gender inequality issue and a grave violation of human rights. Violence against women includes physical, sexual and psychological violence by an intimate partner and non-partner sexual violence" (WHO, 2017). In this paper, the victims are Jordanian women who are viewed as powerless, oppressed, marginalized and inferior in the 
Jordanian social and domestic levels. In Jordan, they suffer from oppression resulting from the patriarchal social construction where the males are always in the lead.

The concept of violence against women encompasses several forms of violence namely: physical, psychological, sexual and emotional sufferings. Haddad (2009) states that violence against women is no longer an individual violent act directed against women, but rather a group of repetitive behaviors that the perpetrator adopts to attain domination and control over his female victim. He adds that violence against women can take several forms and manifestations such as severe and harmful injuries (physical abuse) or repetitive verbal humiliations and abuses (psychological abuse).

With that, violence against women is considered a worldwide social illness that needs to be eradicated due to its dire consequences on the victims. In this paper, however, the scope of violence against women is focused on tribal and conservative societies such as Jordan in which Shalan's novel is set. In the following section, three noticeable forms of violence against women namely physical abuse, psychological abuse and economic abuse will be highlighted and discussed.

\subsection{Physical Abuse}

Physical violence is defined as one of the most widespread forms of violence against women, usually caused by the husband or a male member of the family. This form of violence includes physical harm whether by direct beating or with the use of a tool, and poses serious health and psychological implications on the victim which sometimes result in death as a result of excessive force and severe beatings. "Though reforms and laws to address woman abuse have been a step in the right direction to reduce violence against women, a lot of excuses and concepts adopted by the abuser who abuses his wife, thus reframing their abusive acts as non-abusive" (Human Rights Watch, 2016, p. 2). Women regardless of their race, color, culture, age and social strata are the targets of physical violence that they suffer by means of "being slapped, punched, kicked or thrown, to being scalded, cut, choked, smothered or bitten" (Koss el al., 1994, p. 42) inflicted by physically violent men. AL-Tyawi (2009) asserted that several cases of physical abuse are not reported to the health sector because there is no effective statistical mechanism to collect information and medical records at public and private medical centers. According to Issa's (2018) report on the definition of violence against women and its forms and implications, "depression is considered to be one of the most prevalent psychological diseases at present and is the result of frequent exposures to physical abuse and violence" (Issa, 2018, p. 2). The results of the said study maintained that there is a high percentage of depression among women who have experienced physical violence; hence, effective solutions from the authorities in the health and legal sectors are urgently needed (p. 12). As physical abuse causes the weakening of a female's mental health and self-confidence, it somehow shows that men resort to this violent act to assert their control and superiority over women. Hence, it is no surprise that physical abuse against women is more rampant in communities where ignorance, poverty and deeply-instilled unjust masculine norms still prevail such as in the Jordanian society.

Issa (2018, p. 3) indicates that abuse inflicted by an intimate partner progresses from mild acts such as pinching to more harmful violence such as pushing, slapping and striking. Additionally, Issa (2018) maintains that physical violence can lead to fatal consequences such as murder, suicide and injuries, the increased risk of spontaneous abortion, preterm pregnancy, low birth weight, depression, stress disorders, sleep problems, eating disorders, insomnia, back and abdominal pain, and muscular and digestive disorders; both the husband and society insist that the wife be denied the right to sue her husband if she is physically abused, confirming that physical violence is a tool of masculine mentality that subjugates the existence of women.

\subsection{Psychological Abuse}

Psychological violence refers to all acts of contempt i.e., obscene name-calling, belittling of a woman's successes and physical appearance, ridiculing her feelings with the aim of destroying her personality and controlling her in full, all of which in the long-term can damage her physical health (Jordanian National Commission for Women, 2012). Issa continues to say that "psychological violence involves intimidating women from the consequences of disobedience, destroying their personal property, breaking furniture in the home, or not allowing her to pass or freely move and harassing her by not allowing her to eat or drink in a quiet environment. In addition, the man forces his wife to flirt with him at times that do not fit her, or to persuade her to wear clothes that evoke instinctive instincts" (2018, p. 3). Brassard, Hart and Hardy (1993) describe psychological maltreatment as "a repeated pattern of behavior that conveys to women that they are worthless, unloved, unwanted, or only of value in meeting another's needs" (p. 715). Among of the most often used patterns of psychological violence lies in humiliating and manipulating the victim's emotions. According to Dawaykat (2018), psychological violence against women takes on different forms, and its consequences are severe for the 
victim's personality and future in general: degrading or humiliating her whether in secret or public, attacking her personality or other traits, threatening to make her private photos or details public, and downplaying her value and achievements through remarks such as "you got this work because of my efforts, or you are nothing without me". Additionally, Dawaykat (2018), mentions that intervention and assistance is needed when the female exhibits signs of psychological abuse such as constant unhappiness, worry, fear and insecurity with a strong desire to escape from everything, the feeling of not trusting family or friends, avoiding talking about certain subjects, alongside blaming herself for all her marital problems. Thus, psychological violence causes direct or indirect harm to one's sense of security and stability, leading to feelings of inferiority, lack of self-esteem and depression (Suleiman, 2017, p. 2). Although emotional abuse may not involve physical harm, it still wounds the victim and may even have long-lasting consequences as "the wounds of emotionally abusive relationships are not repaired, and their damage accumulates over time" (Thompson, 1993, p. 1).

\subsection{Economic Abuse}

Economic abuse refers to the husband or intimate partner's act of controlling the ability of his wife or partner to access economic resources, resulting in the latter's inability to financially support her life, and hence rendering her to be economically dependent on her husband or partner. Economic abuse also involves depriving the wife or partner from acquiring money in the present or future by denying her access to education or work (Jordanian National Commission for Women, 2012). From a feminist perspective, economic abuse entails denying women the ability to manage their economic resources or to contribute to financial decisions that affect them and their future, making them fully dependent on others. This includes the denial of the disposition of their property and expenditure for their basic needs, denial of inheritance or expropriation and exposure to economic exploitation (Center for Social Development, 2015). According to Qudah (2014), economic maltreatment is described as a form of control and prevention of women from being economically independent. Specifically, economic abuse can be manifested by the act of stopping a woman from working or maintaining her job, preventing her from completing her studies, using the wife's money or salary without her consent, taking the wife's property against her will or destroying it, exploiting women to do domestic work, childcare and other unpaid family services, controlling the freedom of the wife, threatening to throw the wife and children from home, and exploiting the poor economic situation of the wife.

With that, the problem of economic violence for women "lies in the lack of understanding of the significant role of women in the society, which inevitably leads to the reduction and marginalization of their role in contributing to the building of society as a wife, a mother, a sister, a grandmother and a workmate, stressing that it is the door leading to other types of violence such as verbal violence and moral violence, physical violence, and sometimes sexual violence" (Christine, 2015, p. 1).

\section{Textual Analysis}

\subsection{Physical Abuse in Falling in the Sun}

Physical abuse is a serious and severe social phenomenon with devastating effects on the structure, strength and continuity of society. According to Fida (2016), physical abuse as a social ill is defined as a wide set of violent physical or physiological behaviors carried out by the perpetrator that harms the body and health of the victim including pushing, spitting, pinching, hair pulling, kicking, stabbing, burning, beating, shooting, restricting freedom of movement, causing harm by means of harassment and forcing the victim to do degrading acts. As elucidated earlier, besides physical wounds and pain, the victims also suffer from psychological injuries such as fear, anxiety and post-traumatic stress disorder.

Falling in the Sun is the story of Zahra, a Jordanian woman who grew up in the abusive hands of her father who also abused her mother, Fatima. Her father is a well-known religion-adhering man who always prays and calls for people to abide by Islamic law in their daily life. He treats Zahra badly because he does not favor having a daughter, much less an "ugly" one as he perceives Zahra, which would make it difficult for him to marry her off. He does not want her to continue being his or his son's burden later on in life. Zahra dreams of marrying a man who could save her from her father's unjust treatments. Alas, her dream was shattered when she married Majid who turns out to be an exact replica of her abusive father. Through the course of the story, Zahra continues to suffer in the hands of her father, brother and husband. Having found a space to voice her suffering, Zahra recalls and talks about her father's merciless treatments and brutality towards her and her mother, about how he would beat them due to his misunderstanding of Islamic teachings. The following excerpt clearly depicts the physical violence endured by the female characters in the story:

With or without pretext, he would beat me and my mother. (p. 57) 
A patriarchal social construction encourages a man to control his family through force as a means of discipline. Thus, this clarifies that the father relies on physical violence to maintain his dominance and supremacy within the family. Shalan provides readers with an important understanding of the magnitude of the physical abuse in the current story. Throughout the novel, the heroine, Zahra recalls repeated instances of physical abuse by her father.

My father is nervous all the time. He always beats us up. (p. 63)

As previously mentioned, women, regardless of their social rank and age, are the main targets and victims of physical abuse. The female characters in Falling in the Sun suffer extensively from the physical violence perpetrated by the heroin's father because of their roles as a mother, a daughter and a wife. Zahra reminds the readers that her father's merciless treatments were due to his hatred and anger towards his wife for giving birth to a female as he considers a daughter as a burden.

Zahra also suffers at the hands of her husband who only treated her as an object to fulfill his sexual desires. His animalistic ways borders on rape which causes Zahra physical and emotional harm. Her hidden frustration and anger are evident in the extract below.

My husband didn't care for me, for my life, for my health or even if I was sick or not. The only thing he cares for is making money out of me and being ready to sexually satisfy him. I remember when I told him that I was on my period and was not ready to sleep with him; he felt very angry and started beating me relentlessly and unmercifully. (p. 47)

Pertaining to the extract above, it can be assumed that Zahra's sexual intercourse with her husband falls more under rape than normal sexual intercourse within the folds of marriage. Due to the fact that the issue of rape is a culturally multifaceted matter chiefly powered by masculine ideologies as a sign of unequal powers, several cultures do not address its dire consequences on the victims. As for Jordan, the act of forced sexual intercourse is widespread among Jordanian husbands and wives, becoming an accepted form of the husband's control on his wife. Yet, in the above excerpt, Zahra evidently suffers from physical, psychological and sexual implications.

This unhealthy sexual relationship mixed with the apparent physical abuse confirms the deterioration of her marriage. The brutality and harshness that she experienced in the hands of her husband is also shown in the following extract "I have been remorselessly battered and injured" (p. 36).

Given all the instances of physical abuse experienced by the heroine, it is clear that she and her mother have never been protected by the people who should have been their source of empowerment and security. The next extract describes the intolerable beating tolerated by Zahra in the hands of her brutal father.

Unfortunately, my father was good at grabbing my shoulders, shaking my head and kicking my back. (p. 126)

Without a doubt, the said extracts echo Issa's (2018) notions concerning physical abuse, where the victim can be severely battered and bruised.

\subsection{Psychological Abuse in Falling in the Sun}

Violence against women is often only associated to physical beatings and abuse. However, many women also suffer from psychological abuse of which consequences are equally damaging. Unfortunately, psychological abuse is still seriously overlooked by most, especially its victims. In reference to Issa's (2018) description of psychological abuse previously mentioned, images of psychological violence can also be found in Shalan's novel.

In the story, Zahra's psychological needs are denied by her father, brother, husband and even her society. None of her family members listened to her needs, rights, opinions and even her tired voice, as depicted in the scene of her account of her father's pitiless treatment towards her.

The cruel treatment of my father, which does not please God, introduced me to a psychological state and loss of self. I could not tell whether he was right or not to treat me that way. (p. 33)

As previously mentioned, the concept of patriarchy has been viewed as the root cause of violence against women, where males are often prioritized in most aspects particularly in decision making whereas females are usually excluded even in basic matters such as her own wellbeing. For instance, the issue of forced marriage is an example of psychological abuse where a girl's emotional needs and hopes are overlooked and not taken into account. In Shalan's story, Abu Ahmad, the heroine's father compelled her to marry Majid instead of a man of her own choosing. 
In Jordan, the phenomenon of arranged marriage and traditional marriage is a widespread social aspect that deepens the woman's psychological abuse and marginalization. As said by Issa (2018), disrespecting a woman's will and right to choose her husband is another form of psychological abuse as seen inflicted upon Zahra by her father.

Unluckily, the first and last word in my marriage to my father! He decided that the one my heart chose \{My neighbor\} is not a good suitor to me. (p. 76)

Zahra's mother is yet another example of an emotionally-neglected Jordanian woman trapped in a failed marriage. Her mother says:

When Abu Ahmad refused Zahra's suitor, it reminded me of my deceased father who kicked my lover out when he proposed to me. (p. 79)

As seen in the novel, arranged traditional marriages are a widespread phenomenon in Jordan. In fact, the story presents a worrying situation as a woman's psychological needs are often neglected. Therefore, Shalan depicts normal Jordanian women suffering silently in a patriarchal society that does not support their psychological well-being.

As a wife, she is banned from visiting her neighbors and having social contact with them or even her female friends and relatives. Such restriction from human contact is a form of psychological abuse, leaving the victim feeling isolated and unstable. In patriarchal societies such as that of Jordan, the act of keeping a woman at home is socially supported, supposedly to maintain her good reputation. The aforesaid practice is evident in Shalan's novel, too.

The day I got married was the day I was imprisoned. No more outings, friends and even my close relatives. Majid imprisoned me until I die! (p. 49)

Consistent with Issa (2018), disregarding a woman's psychological feelings in marital and familial relationships is considered as emotional abuse. Consequently, by ignoring Zahra's feelings and psychological condition, her husband, Majid has already abused her emotionally. The aforesaid is clearly evidence in the following excerpt.

Majid has never cared about me! He never paid attention to my sickness and emotions. He only wants me ready for bed and bed only! (p. 62)

As can be comprehended from the aforesaid extracts, Zahra is suffering both psychologically and emotionally due to her husband's blatant and constant disregard of her needs.

\subsection{Economic Abuse in Falling in the Sun}

Although economic abuse is not as harmful as physical and psychological abuse, it remains a problem faced by many women in conservative and poor communities. Like the previously stated forms of violence, economic abuse is also a taboo affair to be discussed among families, particularly the victims. In agreement with Qudah's (2014) description of economic abuse as previously mentioned, images of economic abuse are evident in Shalan's novel as well.

In the story, Zahra's financial standing was blatantly exploited by both her brother and husband. They dismissed her rights and opinions as can be clearly seen in her brother's callous disregard of her right to their inheritance.

Wake up, Zahra! Needless to remind you that women do not inherit in our societies. The inheritance is for males only, and women are enough to eat and drink. (p. 36).

In a male dominated society such that of the Arabs, women are often deprived of their rights and freedom because the Arab society still addresses women as submissive, weak and unable to contribute to the society (Asay, 2015, p. 1).

More importantly, in conservative societies, the rights and freedom of women are lawfully stripped off by man-made legislations in order to fulfill the masculine ego and domination over women. Consistent with Haddad's (2016) description of males in patriarchal communities, they are inflicted with the disease of perceived greatness, narcissism and individuality, which puts women at the mercy of their violent and unfair behavior. Zahra is also financially exploited by her husband who unapologetically takes her salary and inheritance. She is forced to give her salary to her husband in order to avoid his repeated anger and violence.

As a result of this, Zahra's value, humanity and dignity are somewhat diminished. She is reduced to living without any sense of safety and strength, feeling threatened at all times and having no rights on all matters. In masculine societies such as that of Jordan, the act of exclusion and marginalization stands in the way of the social and personal development of the women. Thus, their social standing is reduced in such a way that exposes 
them to all forms of violence by the men including economic abuse.

In our habits, we are never allowed to inherit from our fathers so as not to waste the money to other strange people. Men only inherit! (p. 46)

In line with Qudah (2014), economic abuse in a patriarchal society is manifested by the exploitation of a woman's economic resources by a close male family member. Zahra's husband does his best in dismissing her persona as someone who is financially capable. The following quotation is a strong evident of the aforesaid.

My husband, Majid, worked on eliminating my persona despite my financial ability to do various things for myself, family and others in life. (p. 72)

The practice of taking advantage of a woman's financial status is seen in Shalan's novel through Zahra's brother and husband's intentional insistence to exploit her and take her share of inheritance. In Jordan, the act of taking a woman's financial sources and inheritance is rather prominent which reduces the woman's social rank and value in society. As said by Qudah (2014), disparaging a woman's right to manage her financial matters and work is another form of economic abuse as inflicted upon Zahra by her close family members. The excerpt below depicts Zahra's refusal to assign her share of inheritance to her brother, Ahmad.

Why should I give up my share of my father's money? Neither religion nor logic forces me to do this unreasonable thing. (p. 38)

As seen in the novel, depriving women of their rights to inheritance is a pervasive phenomenon in Jordan. In fact, the story presents the disturbing situation where women's rights, opinions, persona and needs are not respected at all, leading her into a continuous cycle of violence. Shalan clearly sheds light on the fact that ordinary Jordanian women suffer from a patriarchal social context that exploits them financially.

\section{Conclusion}

Numerous contemporary researches, discussions and seminars have focused on the prevalence of violence against women and measures to prevent it. This phenomenon had been highlighted in cooperation with relevant national institutions in order to eliminate it from society, raise awareness about the rights of women and legislations governing those rights, integrate youths in awareness campaigns to combat violence against women, and create a generation of young people capable of resisting and combating aggressive tendencies against women, promoting dialogue among young people to instill a culture of dialogue rather than violence, enhancing the role of battered women in society and mobilizing community support for the respect of women's rights. Regrettably, all these efforts have not resulted in much improvement as the alarming statistics on the number of cases of violence against women continue to rise.

Hence, authors like Shalan play a pivotal role in addressing the issue of violence against Jordanian women and restoring their rights through works of fiction as a platform for additional public discussions and seminars. Based on the fact that "some fictions, and even sub-genres of fiction, have an aim to make truth-claims" (Mikkonen, 2009, p. 146), Shalan's Falling in the Sun can be regarded as a good portrayal of the worrying conditions inflicting Jordanian women. The depiction of the novel's heroine, Zahra, drives the message that violence against women is still a prevalent social ill throughput Jordan. Shalan's novel depicts the magnitude of violence against women in the Jordanian society as an offshoot of male domination that "connotes a denial of autonomy, individuality, and freedom" (Wan, 2003, p. 12) for its victims. More tellingly, her novel makes overt the unhealthy consequences of violence against women among Jordanian female victims.

\section{References}

AL-Tyawi, S. (2009). Domestic Violence against Women in Jordan: Evidence from Health Clinics. Journal of Family Violence, 3(18), 22-34.

Asay, H. (2015). Economic Abuse in Falling in the Sun. Middle East Journal, 2(4), 1-17.

Bataineh, A. (2013). Honor Crime as a Social aspect. Middle East Journal, 2(54), 1-19.

Brassard, M. R., Hart, S. N., \& Hardy, D. B. (1993). The Psychological Maltreatment Rating Scales. Child Abuse \& Neglect, 17(6), 715-729. https://doi.org/10.1016/S0145-2134(08)80003-8

CEDAW. (1992). Convention on the Elimination of All Forms of Discrimination against Women.

Center for Social Development (CSD, 2015).

Christine, A. (2015). Economic Violence among Females in the Arab World. Philadelphia Journal, 6(8), 12-22.

Dawaykat, A. (2018). Future of Violence against Women in Jordan. Amman: Al Yazouri Publishing \& 
Distribution House.

Fararja, M. (2018). Paradigm of Violence against Women: Arab Model. Journal of Intellectual Discourse, 7(16), $183-210$.

Fida Abu Hassan, M. (2016). Physical Violence against Arab Women. Cairo: Cairo Publishing House.

Harne, L., \& Radford, J. (2008). Tackling Domestic Violence: Theories, Policies and Practice. UK: Open University Press.

Hassan, A. (2017). Stream of Consciousness in Falling into the Sun. Philadelphia Journal, 4(2), 18-29.

HRW. (2016). Human Rights Watch.

Issa, M. (2018). Physical and Psychological Violence against Women and Girls in the Middle East. Arab Journal of Social Sciences, 1(7), 1-9.

JNCW. (2006). Jordanian National Commission for Women.

JNCW. (2010). Jordanian National Commission for Women.

John, H. (2009). Literary Theories. Amman: Publishing House.

John, H. (2016). Arab Women between Duties and Rights. Manarah Journal, 13(2), 38-48.

Khadr, A. (2012). Domestic Violence: History and Roots. Dirasat Journal, 2(6), 30-43.

Khawaja, A. (2012). A Comment on Violence against Women. Arab World Journal, 21(2), 38-46.

Koss, M. P., Goodman, L. A., Browne, A., Fitzgerald, L. F., Keita, G. P., \& Russo, N. F. (1994). No Safe Haven: Male Violence against Women at Home, at Work, and in the Community. Washington: American Psychological Association. https://doi.org/10.1037/10156-000

Lateef, A. S. (2017). Resistance to Violence against Women in Jordanian Literature. Eastern Arab Journal, 3(13), $32-43$.

Mikkonen, J. (2009). Assertions in Literary Fiction. Minerva-An Internet Journal of Philosophy, 5(13), 144-180.

Nsour, A. (2008). Arabs, Violence, and Honor Crimes. Al-Anahj Journal, 5(48), 11-24.

Qudah, M. (2014). Violence against Jordanian Women. Dirasat Journal, 1(16), 22-32.

Shalan, S. (2004). Falling in the Sun. Amman: Al Yazouri Publishing \& Distribution House.

Suleiman, S. (2017). Psychological Violence in the Arab World: Its Causes and Consequences. Middle Eastern Journal, 2(5), 1-12.

Thompson. P. (1993). Emotional Abuse: What it is and How it Hurts Us. Minnesota: Hazelden Foundation.

Wan, R., \& Wan, Y. (2003). Female Silence in KS Maniam's Play the Sandpit: A Monologue. GEMA Online Journal of Language Studies, 3(2), 1-17.

\section{Copyrights}

Copyright for this article is retained by the author, with first publication rights granted to the journal.

This is an open-access article distributed under the terms and conditions of the Creative Commons Attribution license (http://creativecommons.org/licenses/by/4.0/). 